\title{
Various Factors of Water Entry and Penetration Through Water Proofing Layer in Wooden Wall Assembly
}

\section{Hiroaki Saito ${ }^{1}$ and Masashi Miyamura ${ }^{2}$}

\author{
${ }^{1}$ Ashikaga University, Ashikaga, Japan 3268558, \\ Phone +81 28422 5674, Fax +81 28462 0976, hsaito@ashitech.ac.jp \\ ${ }^{2}$ National Institute for Land and Infrastructure Management, Tsukuba, Japan 3050802, \\ Phone+81 29864 4339, Fax +81 29864 6774, miyamura-m92ta@mlit.go.jp
}

\begin{abstract}
Rainwater entry and penetration through a waterproofing layer, such as external finishing and sheathing membrane, should be avoided to prevent moisture damage to a wooden wall assembly. However, housing warranty insurance organizations in Japan have reported that deterioration in some wall assemblies was caused by rain penetration, and severely damaged walls were detected in airtight and insulated building envelopes. This paper presents various factors of water entry and penetration of the waterproofing layers in wooden wall assemblies in terms of practical situations, as a part of a research project to reveal the risk of water and moisture accumulation in collaboration with government and industries in Japan. Several experimental works using mock-up specimens replicating a part of the wall assembly were carried out. As for external finishing, the water intrusion was observed not only at the joints but also at the bottom of vented cavities. Although these minor defects must be prevented by proper design and site work, it is difficult to avoid them completely through the construction process and period of use. Indeed, the extent of water entry was affected by various factors such as wall configuration, exposure conditions and so on. Experimental results suggested that various factors, including detail of interface and quality of materials, should be considered to assess service life prediction by hygrothermal analysis.
\end{abstract}

Keywords: Rainwater, Wall Assembly, Waterproofing Layer, Field Survey, Penetration Rate.

\section{Introduction}

Global warming has a significant impact on exposure conditions related to the long-term durability of building envelopes. In humid climate regions, such as coastal areas in East Asia, the frequency of heavy rain tends to increase in recent years. Based on the trends in meteorological data issued by Japan Meteorological Agency, the annual number of days with heavy rain of more than $200 \mathrm{~mm}$ per day increased by 1.5 times in the past decade in comparison with the rate of increase 40 years ago (Japan Meteorological Agency, 2019).

Although the energy-efficient house has recently been required to reduce $\mathrm{CO}_{2}$ emissions even in humid climate regions, a building envelope with higher insulation performance is potentially a concern for a decrease in drying performance (CMHC, 1996; Finch, 2007). An increase in heavy precipitation events might give excessive moisture load to wall and roof assemblies. The housing warranty insurance organizations (HWIO) in Japan reported that more than $90 \%$ in 550,000 cases of insurable contingencies was water leakage and its total number has gradually increased (HWIO, 2017). This investigation for the insurable contingency indicated that $80 \%$ of water leakage occurred in the wall and wall-roof interface (Figure 1a), and that $44 \%$ of it was detected in houses with a shedroof (Figure 1b). Additionally, the percentage of shedroofs 
with short eaves and verges is higher than other types of roof in the insurable contingencies. This finding suggests that short eaves and verges are among the factors causing rain penetration through the waterproofing layer, and this phenomenon should be clarified and also quantified to assess the service life of building envelopes.

With these points in mind, this paper describes an experimental study regarding water penetration through primary and secondary waterproofing layers in wooden wall assemblies in consideration of practical situations. Water spray tests for several types of siding panels and wall-roof interfaces were implemented, and their details were selected from the insurable contingencies in HWIO. Water penetration through the fastener interface of the secondary waterproofing layer was also examined. Based on these results, the importance of the clarification of the water penetration rate as a boundary condition for hygrothermal analysis was discussed.

(a)

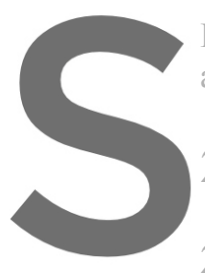

Figure 1. Percentage of and type of roof (b).

2 Water Penetratio

2.1 Outline of Water Spray
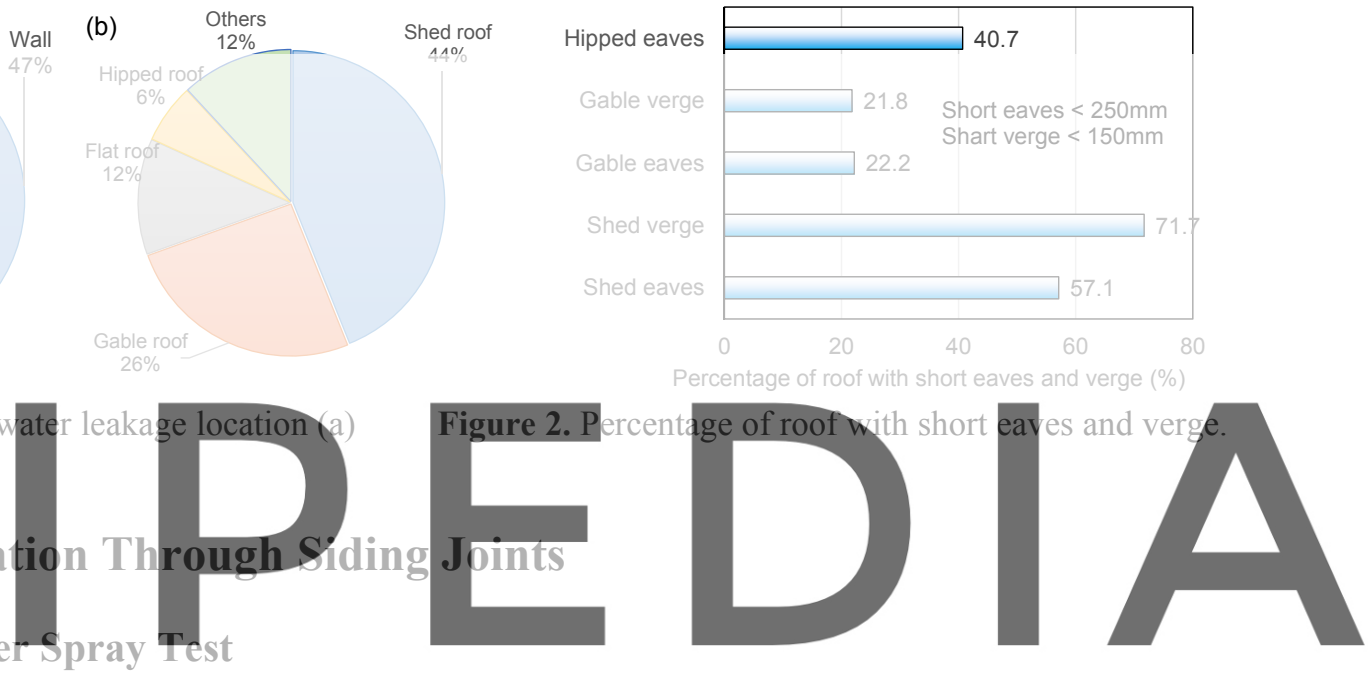

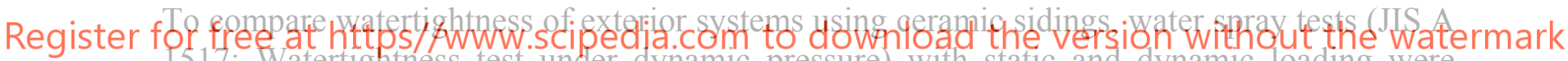
517: Watertightness test under dynamic pressure) with static and dynamic loading were implemented. The ceramic sidings of six products (Sp1 Pp6) were selected to understand the performance of representative products in the siding industry of Japan. All sidings employed a two-way shiplap joint between the top and the bottom, and a metal panel clip to fasten it to the substrate of the wall. The thickness and width of the panel were between 15 and $18 \mathrm{~mm}$ and 300 and $450 \mathrm{~mm}$, respectively. The heights of the shiplap were between 11 and $15 \mathrm{~mm}$.

Since the outside dimensions of the opening of an airtight box with water spray nozzles were $1.98 \mathrm{~m}$ by $1.98 \mathrm{~m}$, two types of siding panel measuring $0.91 \mathrm{~m}$ by $1.98 \mathrm{~m}$ were fixed to a wood frame, side by side, as specimens (Figure 3). The sprayed water was uniformly applied at a rate of $4 \mathrm{~L} /\left[\mathrm{m}^{2} \mathrm{~min}\right]$ across the exterior of the specimens in Case 1 and Case 2, as shown in Figure 4. A rate of $0.3 \mathrm{~L} /\left[\mathrm{m}^{2} \mathrm{~min}\right]$ of the sprayed water was applied in Case 3. Static pressure differences through the siding panel were increased stepwise by $150 \mathrm{~Pa}, 240 \mathrm{~Pa}, 350 \mathrm{~Pa}$, and $470 \mathrm{~Pa}$ with static loading. In addition, dynamic loading tests were implemented in Case 2 and Case 3. Water penetrating the inner plane through the shiplap joints was collected at the bottom of the specimen, and weighed to quantify the overall penetration rate. 


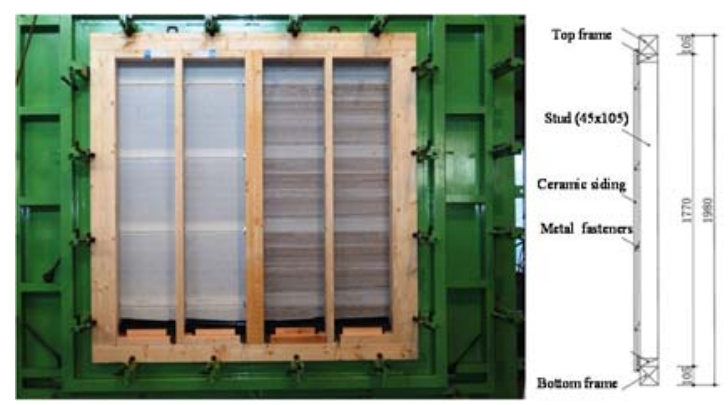

Figure 3. Specimens fixed to airtight box.

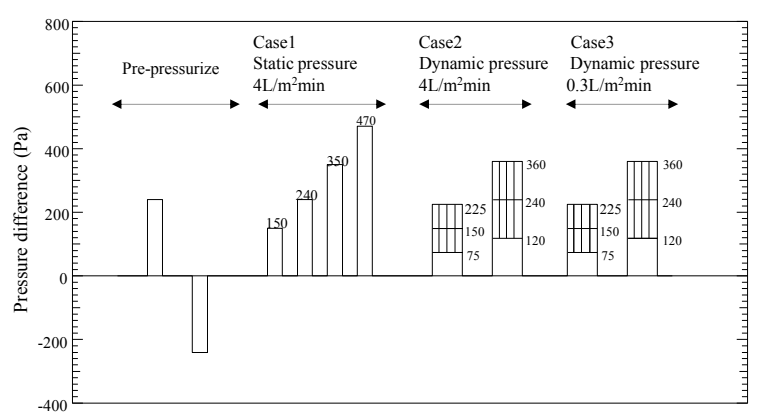

Figure 4. Pressurize process in water spray tests.

\subsection{Water Penetration Rate from Siding Joints}

The quantity of penetrating water and the water penetration ratio in Case 1 are shown in Figure 5 and Figure 6, respectively. The water penetration ratio means the ratio of the penetrating water and sprayed water. The quantity of the penetrating water in Sp1 and Sp2 exceeded $0.3 \mathrm{~L} / \mathrm{min}$ $\mathrm{m}^{2}$ in the range beyond $240 \mathrm{~Pa}$. This value is approximately equivalent to $8 \%$ of the water penetration ratio in Figure 6. These values of the other specimens were less than $0.1 \mathrm{~L} / \mathrm{min}^{2}$ and 3\%. Figure 7 shows the water penetration ratio in dynamic presure conditions (Case 2, Case $3)$. Although the values in Case 2 are less than in Case 1, in the event of an equivalent average pressure difference, those in Case 3 are larger than in Case 1. It is speculated that accumulated
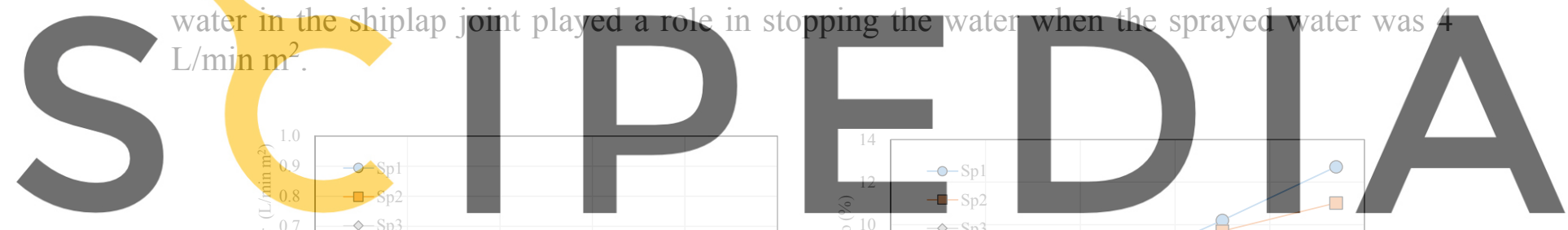

Register for free at https//www.scipedia.comp to dơ̆ ${ }^{8}$ nload the version without the watermark

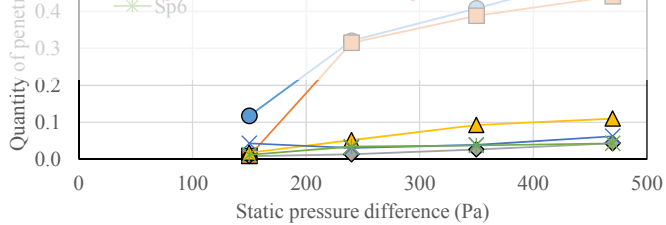

Figure 5. Quantity of penetrating water in Case 1.
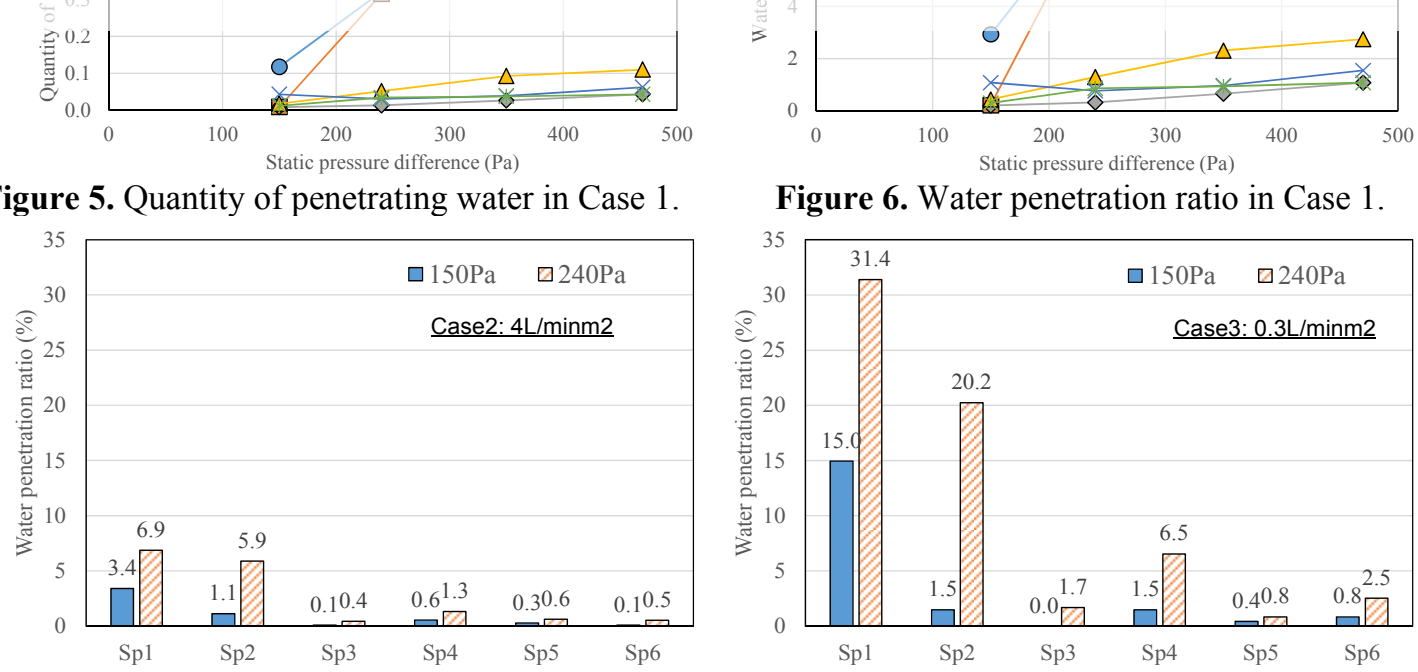

Figure 6. Water penetration ratio in Case 1 .

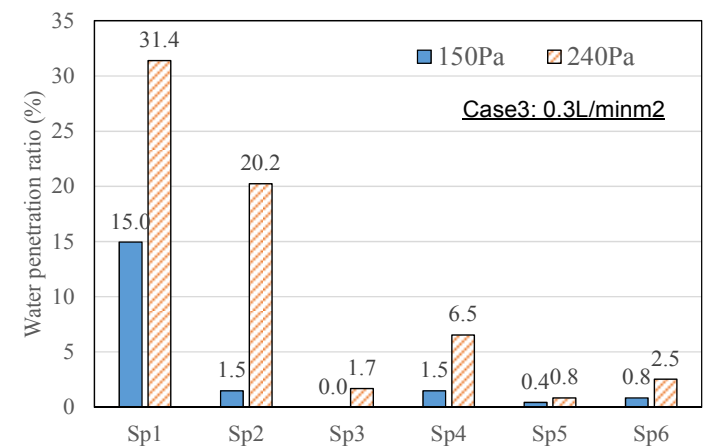

Figure 7. Water penetration ratio in dynamic test (left: Case2, Right: Case3). 
According to past research (Sahal and Lacasse, 2005) regarding rainwater penetration through basic components of wall assembly, the quantity of water penetration through electrical outlets and vent ducts was approximately less than $0.25 \mathrm{~L} / \mathrm{min}$ at $300 \mathrm{~Pa}$ of static pressure difference. However, water penetration from these shiplap joints in $\mathrm{Sp} 1$ and $\mathrm{Sp} 2$ reached 0.4 $\mathrm{L} / \mathrm{min} \mathrm{m}^{2}$, meaning that $12 \mathrm{~L} / \mathrm{min}$ of rainwater enters into the vented cavity when the wall area is $30 \mathrm{~m}^{2}$. This result indicates that dispersion of the water entry in siding products cannot be neglected in determining the proper configuration of vented cavity in terms of drainage and drying performance.

\section{Water Entry at the Top and Bottom of an Exterior with Short Eaves}

\subsection{Outline of Wind and Rain Blowing Test}

In this section, a wind and rain blowing test was implemented to verify the risk of water leakage at the roof-wall interface and the bottom of the vented cavity, as shown in Figure 8. Four types of mock-up specimens incorporating the roof-wall interface were assembled in consideration of actual detail of the insurable contingencies. The width of the specimen was $1820 \mathrm{~mm}$, and the length of the eaves from the center of the beam was $95 \mathrm{~mm}$. A vented cavity connected the attic of the specimen with the top of the wall. Sheathing board such as plywood was not installed in the inner layer of the housewrap, in order to confirm water penetration through an overlap of the housewrap due to water splashing from the bottom of the vented cavity. Airtightness inside the wall was secured by

\section{differ in details around th} plywood, and additiona attached in Type 2 or Typ and a bargeboard was front of a blowing device, and the roof-wall
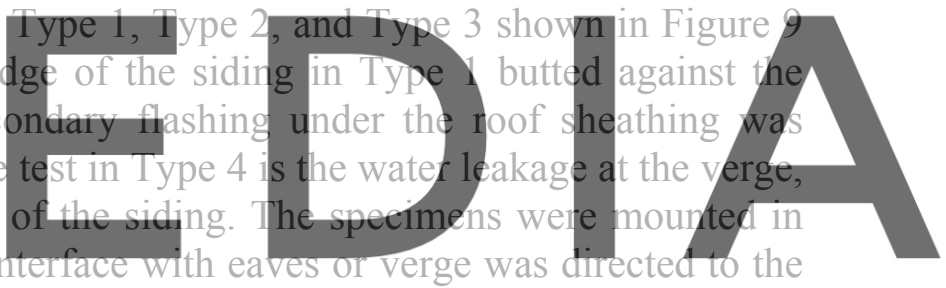
center of the air outlet of the blower. The levels of wind velocity were $5,10,15,20 \mathrm{~m} / \mathrm{s}$, which

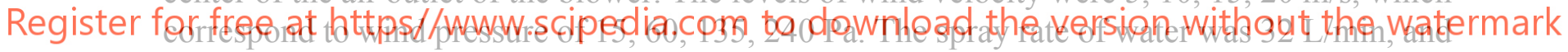
duration time of the test was 15 min.

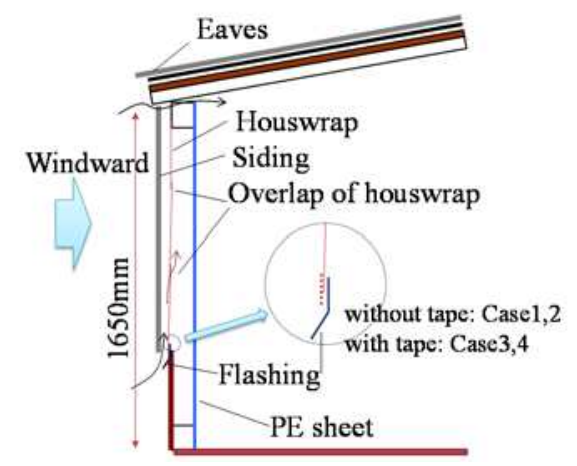

Figure 8. Mock-up specimen for blowing test.

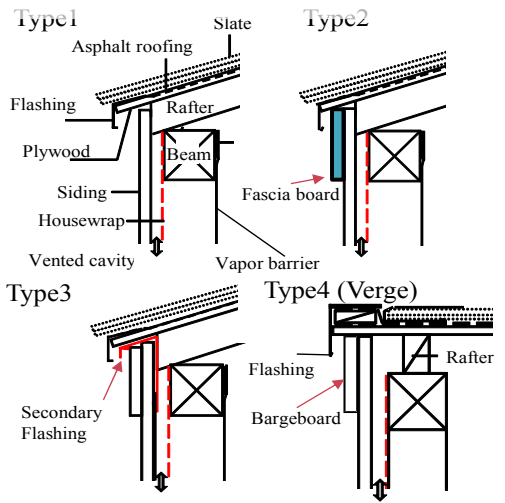

Figure 9. Detail around the eaves and verge.

\subsection{Wind Velocity for Onset of Water Leakage and Wetting}

Water leakage through the exterior layer in the wind - rain blowing test was confirmed by visual 
observation from inside the specimen. Table 1 shows wind velocity for the onset of water leakage. Water splashing into the bottom of the cavity was observed on all specimens with a wind velocity of $5 \mathrm{~m} / \mathrm{s}$ and above. Continuous splashing through the roof-wall interface was observed in Type 1. Type 1 carries the risk that rainwater penetrates into the thermal insulation layer. Although Type 2 presented better waterproof performance than Type 1 due to the addition of a fascia board at the roof-wall interface, water penetration into the rear face of the housewrap was observed from $15 \mathrm{~m} / \mathrm{s}$. Secondary flashing at the top of the siding in Type 3 prevented the water penetration even in $20 \mathrm{~m} / \mathrm{s}$. The result on the verge of the roof in Type 4 was approximately equivalent to Type 2 .

Table 2 shows the relation between wetting location and wind velocity. Wetting at the ground sill was observed from $5 \mathrm{~m} / \mathrm{s}$ in Type 1 and Type 2, because of a lack of tape at the bottom of the housewrap. Splashing water reached the overlap of the housewrap at $15 \mathrm{~m} / \mathrm{s}$, where the height was $1 \mathrm{~m}$ above the bottom of the vented cavity. Although such excess wind pressure at the bottom of the wall generally does not occur in urban areas, a vented cavity above a lean-to roof has the potential to cause pressurization.

These results indicate that imperfect detail for waterproofing at the roof-wall interface causes water penetration not only into the vented cavity but also into the rear of a secondary waterproofing layer, such as the housewrap. In addition, strong winds exceeding $20 \mathrm{~m} / \mathrm{s}$ increase the water penetration that accelerates water absorption at the surface of sheathing board in wall assemblies. It is necessary for roofs with short eaves to assess safe detail against winddriven rain.
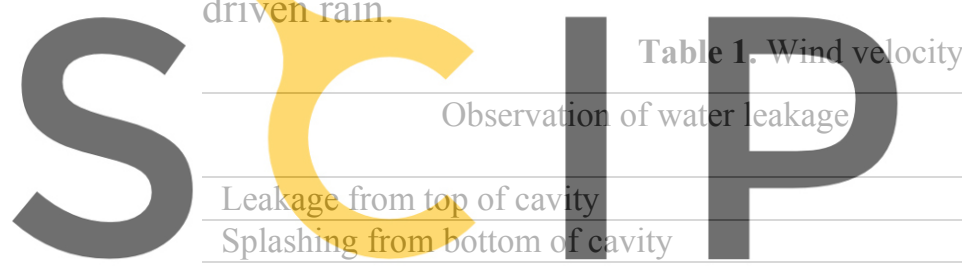

Penetration into the rear of the housewrap from the top

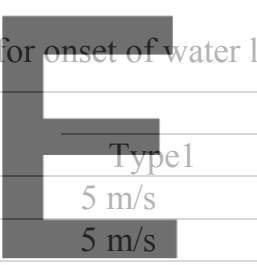

$5 \mathrm{~m} / \mathrm{s}$

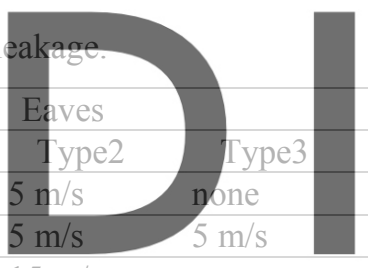

none

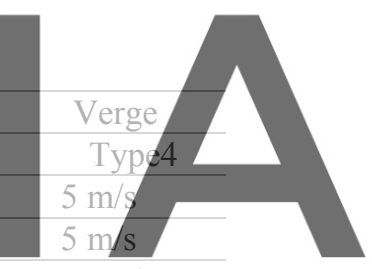

$15 \mathrm{~m} / \mathrm{s}$

Register for splashing inte the rear of the housewrap from the bottom $5 \mathrm{~m} / \mathrm{s}$ ad the $5 \mathrm{~m} / \mathrm{s}$.

Table 2. Relation between wetting location and wind velocity

\begin{tabular}{lcccc}
\hline \multicolumn{1}{c}{ Wetting location } & \multicolumn{2}{c}{ Eaves } & \multicolumn{2}{c}{ Verge } \\
\cline { 2 - 5 } & Type1 & Type2 & Type3 & Type4 \\
\hline Ground sill* & $5 \mathrm{~m} / \mathrm{s}$ & $5 \mathrm{~m} / \mathrm{s}$ & none & none \\
\hline Sheathing roof board & $5 \mathrm{~m} / \mathrm{s}$ & $5 \mathrm{~m} / \mathrm{s}$ & none & $5 \mathrm{~m} / \mathrm{s}$ \\
\hline Rafter & $5 \mathrm{~m} / \mathrm{s}$ & $5 \mathrm{~m} / \mathrm{s}$ & none & - \\
\hline Pole plate & $5 \mathrm{~m} / \mathrm{s}$ & $15 \mathrm{~m} / \mathrm{s}$ & none & $5 \mathrm{~m} / \mathrm{s}$ \\
\hline Purlin & - & - & - & $10 \mathrm{~m} / \mathrm{s}$ \\
\hline * due to splashing water from the bottom of cavity & & &
\end{tabular}

* due to splashing water from the bottom of cavity

\section{Water Penetration through Secondary Waterproofing Material}

\subsection{Water Penetration through a Pinhole in a Water-Resistant Barrier}

Nails and staples are generally applied to secure secondary waterproofing material, such as permeable polymer houswrap and asphalt-impregnated felt. However, the fastener interface 
carries a risk of water penetration, and past research (Saito, 2015) has tried to quantify water penetration rate through pinholes in roof underlayments after exposure to cyclic temperature variation. To clarify the dispersion of the risk, water penetration tests for representative products were conducted, and reported in this section.

\subsection{Outline of Water Penetration Test for Fastener Interface}

\subsubsection{Case 1 (Without Outdoor Exposure)}

The test protocol for the water penetration test was in accordance with Japanese Architectural Standard Specification JASS 12 [Roof construction] (2005, AIJ). Seven products of asphaltimpregnated felt (AF), two products of modified asphalt-impregnated felt (MF), and three products of permeable polymer housewrap (HS) for secondary waterproofing material of wall assembly were selected as the test samples. The AF and MF were immersed in calcium hydroxide for 168 hours before fastening on the substrates, while this alkali treatment was not performed on HS. These test samples were set on substrate and fastened by staples. Two products of staples with $13 \mathrm{~mm}$ and $19 \mathrm{~mm}$ leg lengths were employed as the fastener for AF and MF, and those with $13 \mathrm{~mm}$ leg length were used with HS. Water column containers were placed on the fasteners of the specimen, and colored water was injected into them, as shown in Figure 10. The potential of the hydraulic pressure was set at 30, 50, 100, $150 \mathrm{~mm}$ of height, and water penetration was confirmed by visual observation of the colored water leaking after 24 hours. Three spots for test target with the water column container were prepared for each AF, 6 for MF, and 9 for HS, respectively. Table 3 shows test cases and exposure conditions.
4.2.2 Case 2 (After Outdoor Exposure)
Water penetration tests in Case 2 were performed on three products of HS and one product each of $\mathrm{AF}$ and MF. Each sample was fastened to the substrate of plywood using the staple, and the

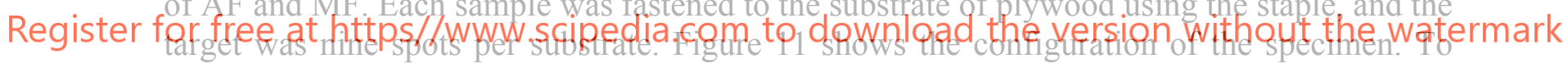
consider the impact of exposure conditions on an actual construction site before installation of the exterior finish, the specimens were exposed to an outdoor environment on a 30-degree angle from the horizontal. The water penetration test was performed after the exposure for 2 weeks in winter. The water level for the water penetration test in Case 2 was only $30 \mathrm{~mm}$.

Table 3. Test cases for water penetration test.

\begin{tabular}{|c|c|c|c|c|}
\hline Case & Sample & $\begin{array}{l}\text { Leg length of staple } \\
(\mathrm{mm})\end{array}$ & $\begin{array}{l}\text { The number of pinholes } \\
\text { [The number of products] }\end{array}$ & $\begin{array}{c}\text { Exposure condition } \\
\text { before the test }\end{array}$ \\
\hline \multirow[t]{5}{*}{1} & $\mathrm{AF}$ & 13 & $21[7]$ & \multirow{4}{*}{$\begin{array}{c}\text { Alkalin for } 168 \\
\text { hour }\end{array}$} \\
\hline & & 19 & 21 [7] & \\
\hline & MF & 13 & $6[2]$ & \\
\hline & & 19 & $6[2]$ & \\
\hline & HS & 13 & 9 [3] & - \\
\hline \multirow[t]{3}{*}{2} & $\mathrm{AF}$ & 19 & $9[1]$ & \multirow{3}{*}{$\begin{array}{c}\text { Outdoor } \\
\text { environment for } \\
\text { 7days }\end{array}$} \\
\hline & MF & 13 & $9[1]$ & \\
\hline & HS & 13 & $27[3]$ & \\
\hline
\end{tabular}

AF: Asphalt-impregnated felt 430, MF: Modified asphalt-impregnated felt, HS: Permeable polymer housewrap 


\subsection{Rate of Fastener Interface Securing Watertightness}

\subsubsection{Case 1 (Without Outdoor Exposure)}

Figure 12 shows the relationship between the rate of the fastener interface securing watertightness and the water level. Water leakage was observed at $30 \mathrm{~mm}$ of the water level in HS, and all points of HS allowed water penetration through the fastener interface. Contrarily, $\mathrm{AF}$ and MF indicated higher performance for watertightness. However, water leakage in AF and MF was detected from $50 \mathrm{~mm}$ of water level, and half of the test spots allowed water penetration at $150 \mathrm{~mm}$. Although this experiment in Case 1 showed the vulnerability of HS, it could not indicate a difference between $\mathrm{AF}$ and $\mathrm{MF}$ in terms of seal performance at fastener interface.

\subsubsection{Case 2 (After Outdoor Exposure)}

Table 4 shows the rate of watertightness after exposing the specimens in an outdoor environment for two weeks. Dispersion in the difference of the spots was not indicated in each waterproofing material. Although water penetration was detected on AF and HS, MF secured watertightness on all spots of the fastener interface even after outdoor exposure. In general, it takes more than a week for the installation of exterior finishing after fastening the waterproofing material in construction sites. The differing results between Case 1 and Case 2 suggested not only vulnerability in AF but also durability in MF against outdoor exposure, taking into account

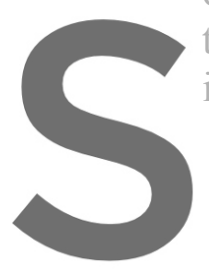
the construction schedul

is important in terms of

Register for free at https/fwwwwsarercipedia.com to
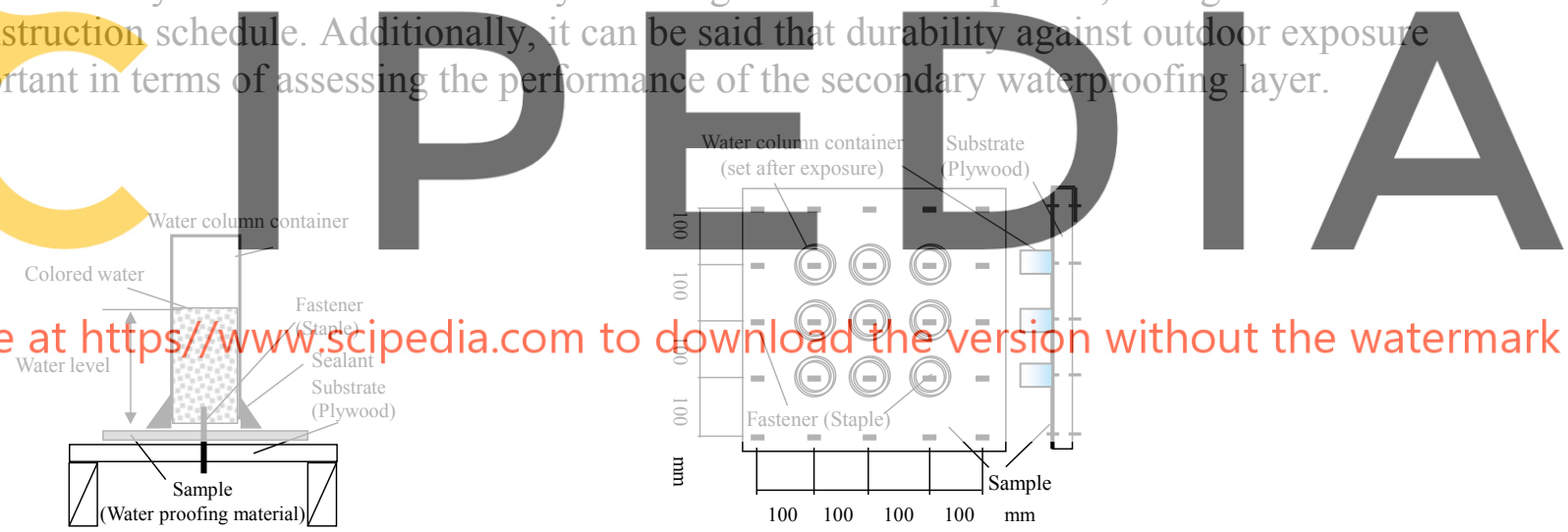

Figure 10. Setup for water penetration test.

Figure 11. Configuration of specimen (Case 2).

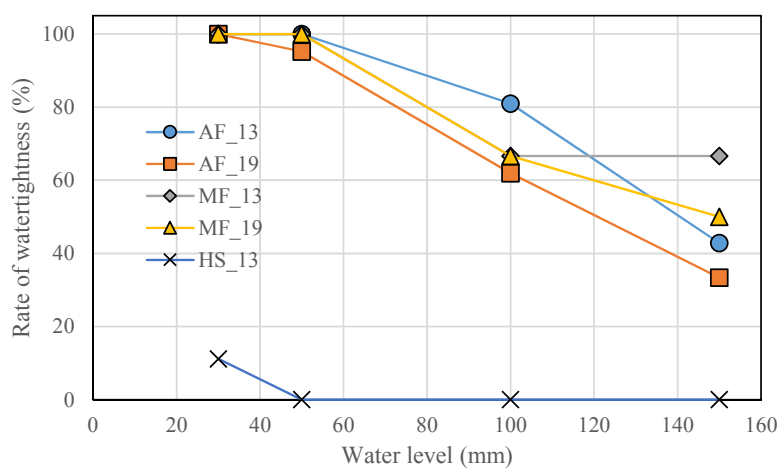

Table 4. Rate of watertightness in Case 2.

\begin{tabular}{cc}
\hline $\begin{array}{c}\text { Waterproofing } \\
\text { material }\end{array}$ & $\begin{array}{c}\text { Rate of watertightness } \\
(\%)\end{array}$ \\
\hline AF & $0[0 / 9]$ \\
\hline MF & $100[9 / 9]$ \\
\hline HS & $0(0 / 9)$ \\
\hline
\end{tabular}

Figure 12. Rate of fastener interface securing watertightness in Case 1. 


\section{Conclusions}

To confirm the vulnerability of the primary and secondary waterproofing layer to water entry, water penetration tests were implemented on vulnerable parts, such as siding joints, wall-roof interfaces and fastener interfaces. The quantity of penetrated water in the worst specimens exceeded $0.3 \mathrm{~L} / \mathrm{min} \mathrm{m}^{2}$ at $240 \mathrm{~Pa}$ of pressure difference, and this value is greater than water penetration from electrical outlets and vent ducts in past research (Sahal and Laccase, 2005). The significance in this experiment is that products with vulnerable watertightness occasionally exist, even though there was no remarkable difference in the specification. As for water entry at a wall-roof interface with short eaves, wind and rain blowing tests indicated that conventional details, using fasciaboard and bargeboard, are not useful in preventing water entry into the rear of the siding. Additionally, splashing water reached the pole plate and accumulated on it, when the wind pressure increased. Water penetration through permeable polymer housewrap was confirmed at the fastener interface. The watertightness of AF significantly decreased in outdoor exposure of just 2 weeks.

Although this paper merely addressed a few phenomena relating to water leakage, the results suggest that various factors, such as detail of interface and quality of materials, have significant impact on the extent of water leakage. Lately, consideration of rain penetration in hygrothermal analysis has been recommended in evaluation methods such as the ASHRAE Standard 160 (ASHRAE 2009), and a certain rain penetration ratio is provided. However, results in this paper imply that this value should be modified by the various factors discussed in order to assess the

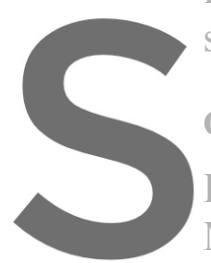
service life of buildin ORCID

Hiroaki Saito: https: Masashi Miyamura: ht
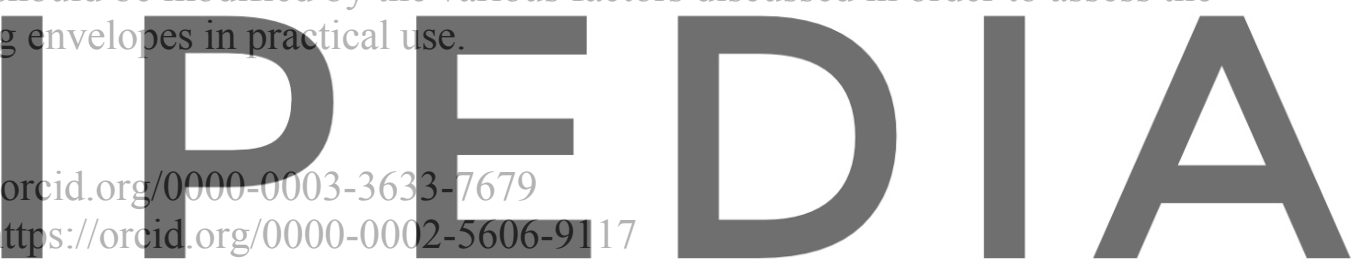

References

Register for free at https//www.scipedia.com to download the version without the watermark

Japan Meteorological Agency (2018). 2017 edition of Climate Change Monitoring Report

Canada Mortgage and Housing Corporation (1996). Survey of building envelope failures in the coastal climate of British Columbia, Columbia, Report prepared by Míorrison Hershfield Limited

Finch, G. and Straube, J. (2007). Hygrothermal Performance and Drying Potential of Wood Frame Rainscreen Walls in Vancouver's Coastal Climate, Proceedings of 11th Canadian Conference on Building Science and Technology, Banff, Alberta

Japanese Standard Association (1996). JIS A 1517: Windows and doorsets - Watertightness test under dynamic pressure. (in Japanese)

Sahala, N. and Lacasse, M. (2005). Water entry function of a hardboard siding-clad wood stud wall, Building and Environment, 40, 1479-1491. doi:10.1016/j.buildenv.2004.11.019

Saito, H., (2015). Hygrothermal Analysis for Pitched Roof in Consideration of Water Penetration through Pinholes of Roofing Underlayment Assemblies, Roofing Research and Standards Development: 8th Volume, ASTM STP 1590, 206-222

Architectural Institute of Japan (2005). Japanese Architectural Specification Standard JASS 12 (in Japanese) ASHRAE (2009). Criteria for Moisture-Control Design Analysis in Buildings. ASHRAE Standard 160. 